\title{
Ergonomic Concerns in Enterprise Resource Planning (ERP) Systems and Its Implementations
}

\author{
Ram R. Bishu \\ Department of Industrial and Management Systems Engineering, University of Nebraska- \\ Lincoln \\ Rbishu@engvms.unl.edu
}

Brian M. Kleiner

Department of Industrial Engineering, Virginia Tech

Bkleiner@vt.edu

Colin G. Drury

Department of Industrial Engineering, University at Buffalo

Drury@buffalo.edu

Keywords ERP systems, Implementation, Ergonomics

\begin{abstract}
Enterprise Resource Planning (ERP) systems promise to improve the overall effectiveness of organizations through integration of all the functionalities within the organizations. Further, within the context of "managing the supply chain", ERP systems promise to include even more coverage, in essence automating the entire Chain. This is achieved through all encompassing software. Over the last four years, success stories of ERP implementations have been few and far in between. Besides high initial start-up costs and high implementation costs, the implementation process have been problematic due to lack of due consideration to the 'human' component. Consequently, many companies have minimized their losses by abandoning their projects mid-course. This paper takes the perspective that ERP is in desperate need of ergonomic research, design and implementation to minimize the financial and human costs currently being experienced.
\end{abstract}

\section{INTRODUCTION}

Enterprise Resource Planning (ERP) systems are commercial software packages that promise seamless integration of all the information flowing through a company. It attempts to integrate all departments and functions 
across a company onto a single computer system that can serve all those different departments' particular needs (Davenport, 1998). ERP systems have evolved from earlier production planning and control approaches, such as Materials Requirements Planning (MRP) and Manufacturing Resource Planning (MRP II) systems. These helped plan and schedule production by expanding a product order into a bill of materials, and scheduling ordering and manufacture of components and sub-assemblies. The newer ERP systems integrate a number of additional functions, such as product design, sales and distribution, order entry, billing, and even human resource functions. In other words ERP system integrates all the functions in an organization, at all business units, across all global regions. Major Contemporary ERP vendors are SAP, BAAN, PEOPLESOFT, and ORACLE. Each of these ERP systems has evolved from their respective specialized software programs. For example SAP evolved out of an integrated finance and cost module, while PEOPLESOFT evolved out of a specialized human resources module. The best known among these is SAP [Taylor, 199X].

ERP systems typically have three layers of architecture (Figure 1). At the top layer is the user interface containing all the application modules. The system software is the middle layer, while the database is located at the bottom. These systems are transparent to the underlying database. The application modules for SAP include human resources (HR), quality management $(\mathrm{QM})$, materials management $(\mathrm{MM})$, production planning $(\mathrm{PP})$, sales and distribution (SD), and plant maintenance (PM).

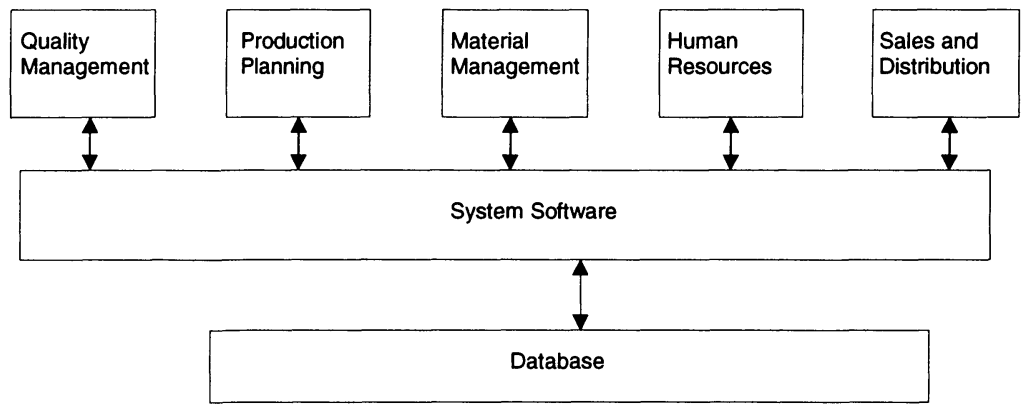

Figure 1:Three layers of ERP systems architecture

\section{ERP}

Three major reasons can be provided for the need of such systems. First, is the global nature of business itself in the $21^{\text {st }}$ Century. Businesses have gone global to make use of differences in economy and cost structure among nations. For example, the trend in manufacturing is to move from 
first world countries to second and third world nations. Global production and global distribution implies a clear understanding of the various ethnographies, cultural differences, regulatory differences and other such differences. There is certainly a need for a global information system. Such a system would manage all these differences in a timely and reliable fashion and provide solutions in real time. Second, is the proliferation of the internet, intranet and extranet across the globe. A few years ago, fax and telephones were the primary mode of communications among facilities located in different parts of the globe. With the internet, the communications environment has changed. Intranets and extranets have provided the needed security in communications. Hence, an organization headquartered in, Detroit, USA, can have transactions immediately at its plant in, San Paulo, Brazil. Intranets and extranets provide both the media and the correct amount of security for plant-to-plant transactions within a business. Third, software is needed which would integrate all functions within a unit, all units within plant and all plants within an organization. ERP systems are company-wide software systems that integrate all the functions within an organization. ERP combines all of them into a single, integrated software program that runs off a single database so that the various departments can more easily share information and communicate with each other. However, the integration can have tremendous effect if the software is installed correctly. The ERP suppliers, such as SAP, BAAN, Oracle and others have shown that such integration can be the basis for large cost savings in many different organizations from manufacturing, through service and maintenance companies, to government departments. Indeed, cost savings driven by customer demand are typically cited as the main reason for ERP implementation.

Implementations of ERP systems are struggling throughout the world. They take too long, cost too much and fail to deliver the promised benefits of competitive advantage and cost reduction (Buckhout, Frey and Nemee, 1999). In a study to look at the effectiveness of implementation in companies with more than 500 million sales, it has been reported that the average cost overrun is $175 \%$; the average schedule overrun was $230 \%$, and the average slide in functional improvements was an astonishing 59\% deficit (Buckhout, Frey and Nemee, 1999). By its nature, software that promises to integrate all the functions within a unit and all the units within an organization will be complex. In addition, ERP software developers claim that the software, with all its suite of functional modules, is sufficiently generic to be adaptable to the needs of a number of diverse organizations. The only thing more complex than the software itself is the process of its implementation. The steps in the implementation are development of an 
implementation project plan, determination of existing processes ("as is status"), gap analysis and business process reengineering, develop a conceptual design, design interfaces and enhancements, detailed design and systems set up, preparations for going live, productive operation and post implementation support. The scales of business process reengineering and customization tasks involved in implementation process are reported as one of the major reasons for ERP dissatisfaction. It has also been reported that the ratio of implementation costs to software costs is in the range of 5:1 to 7:1 (Scheer et al, 2000).

Development of an implementation project plan would include laying out a time line, resource plan and other project details for the implementation process. Determination of the existing process can range in complexity depending on the organization size and type.

While the basic functionality such as material management, MRP, Quality control and others are common across all organizations, their depth and breadth will vary considerably between organizations. Given that the basic system software is generic to be used across all industries make the implementation process much more complex. The main process in implementation is configuring the software to suit the client organization. There are two issues of concern here. Organizations need to make the correct strategic choices to configure the system, and need to address the ergonomics of implementation process. It is not difficult to visualize implementation difficulties if one realizes that the same generic software is being configured for two large organizations that have little, except size, in common as in Monsanto, the chemical giant and John Deere a farm equipment giant.

The costs of ERP implementation are high, as would be expected for such a pervasive system. For large companies, costs often exceed $\$ 100$ million, with installation costs typically over twice software licensing costs (Hughes, 1999). Installation costs are so high because in most cases the ERP software demands that particular business practices be changed before the software can be installed. In addition, the migration to ERP can take several years.

If costs are high, so too are potential benefits. The software suppliers and customers claim annual savings of $10 \%$ to $50 \%$ of installation costs, and payback periods as low as two year. Major savings come from elimination of legacy software systems, reduction in software maintenance costs, and adoption of the business practices necessary to run the software.

\section{IMPLEMENTATION OF A TYPICAL ERP SYSTEM}




\section{Phase 1: Definition Phase}

In this phase the organization's objectives for using ERP system are defined, as are its current processes. An initial comparison is made between existing processes and ERP system's functionalities. The project team is assembled and its training needs are detailed. Typically the end product at this juncture is a workable project plan. Integration is the keyword in ERP systems. They operate on a hierarchical level with the highest level defining the organization as a whole and the next level defining the different functional divisions or plants. Each of the plants may be in different geographic regions in a global economy. The complete system environment with its respective settings is decided in this phase.

The scoping phase is an important part of the implementation process. A complete list of existing processes are developed and compared against existing functionality of the system. The comparisons often result in one of the three options: (1) either the system functionality matches completely, in which case prototype solution development is the next stage; (2) there is a gap which may result in system modification (very rare); or (3) there may be a gap that may result in business process reengineering. In short this is the 'problem definition and solution development phase' of the implementation process. Templates for design solutions, interfaces, and enhancements to be developed are defined. The conceptual design solution thus created is tested for completeness and functionality.

\section{Phase 2: Detailed Design and System Set-Up}

This is one of the critical phases of implementation. In the previous phase the design solution was conceived. In this phase the actual design is performed initially on some trial (or training) system. The global system parameters are defined. Functional designs are configured. Configuration is setting all the definable parameters in the software to meet clients' needs. Often the implementation process spins out of control here, because the company has not made the required strategic choices here, or the software needs major modification to meet the clients' needs. Master data sets are decided and entered. Data transfer from legacy systems are detailed here. Interfaces are programmed, as are enhancements, and modifications. Design decisions on gaps between available functionality of ERP systems and required functionality of clients are made in this phase. Reporting strategy decisions are also made. Report needs are established, formats designed and programmed. Archiving concerns and change management concerns are also addressed at this stage. Finally the prototype design solution, one that has been constructed on a training (often called SANDBOX) environment is reviewed with users, validated and tested. 


\section{Phase 3: Preparations for Going Live}

Typically ERP systems implementation processes proceed from one environment to others, before finally going live. For example, the first construction of the design solution will be performed in a 'free-for-all-playwith-it-as-you-wish' environment. Subsequently, the development will be done in a more restricted sense with some real time data in a cleaner environment (often called PRISTINE environment). Validation, testing and quality checks are then performed in this environment. Once it is ensured that the system works, construction of the solution begins in what is called the DEVELOPMENT environment. This is the equivalent of a robust working model that is ready to be used in the shop floor, in a manufacturing sense. This system has all the master data transported from legacy systems. The next step is creation of a "Go-Live Plan".

Production systems, as they are called, are the final versions of the ERP systems that are to be used eventually by users. The configuration of the production system, procurement of the production system and creation of user documents are performed at this stage. It is relevant to note that the system, in all its totality, is transported electronically from the development to production environment. The development version is an actual working model. Future changes will be made first to the development system, verified for accuracy and working and then transported to the production system. Training users is an important step in this phase. It includes creation, preparation and delivery of the training program. The last function to be performed in this stage is design and creation of user documentation.

\section{Phase 4: Productive Operation}

This is typically a post implementation operation. It involves providing support to users and provision of help desk etc. In many ERP implementations there is significant "rework" due to necessary plant-specific customization or because the vendors do not adequately train users, to effectively use the software.

\section{THE PROBLEMS IN IMPLEMENTATION}

As stated earlier in this paper, implementations of ERP systems are struggling throughout the world. They take too long, cost too much and fail to deliver the promised benefits of competitive advantage and cost reduction. Why is this so? Some of the problems lie with the enormous technical challenges of rolling out enterprise systems, which are large complex pieces of software. Business problems, i.e., lack of corporate 
ability to take tough business decisions needed for implementation are the other reasons quoted (Davenport, 1998). Finally implementation processes are complex and need careful management attention, planning and resources. Companies need to establish guidelines for involvement-or 'rules of engagement' for different levels in the organization so those team members get to participate in an effective way.

\section{RESEARCH AGENDA FOR ERGONOMICS}

There are a number of ergonomic research issues with the design and implementation of ERP systems. However, the importance of the ergonomist's role has not been realized either by the ERP community or addressed by the ergonomic community. There are three main related pitfalls in system design; (1) technology-driven design; (2) leftover approach to function and task allocation and (3) failure to attend to sociotechnical system characteristics (Hendrick and Kleiner, 2000). ERP evolution has exhibited all three pitfalls. Clearly, the software advances coupled with aggressive marketing tactics have dominated the system design process. Essentially, an implicit design goal has been to maximize the level of automation. If a function could be automated, it was done. This has lead to a leftover role for the human decision-maker. In many cases, for example, inadequacies in the software resulted in a human endeavor to program patches or additional programs. What is needed is a deeper understanding of the socio-technical characteristics of the supply chain and an answer to the question, "what should be automated". This has also been raised by Taylor (199X), who suggests using a socio-technical systems approach to ERP implementation.

In a macroergonomic sense there are mismatches among roles of members on the implementation team as well. From a user viewpoint, user training warrants attention and finally, from a human-computer interaction standpoint the system itself is a maze of screens navigable through a series of hierarchical menus. While some attention has been given to the actual screens, cognitive engineering considerations in the design of the information architecture underlying these screens appear to be missing. Overall the system and the implementation process itself appear to be technology-centered rather than human- centered.

\section{Implementation issues}

Conceptually, the implementation process follows an interaction model comprising three teams: (1) a team of functional experts (users), (2) a team of implementation experts (primary implementing vendor) and (3) a team of 
ERP experts (Figure 2). Further the implementers themselves are from two groups-staff from a primary implementing vendor organization and consultants.

The ERP professionals are experts in software. Usually they belong to the 'product support group' or the 'after sales service group' of the organizations that make and sell the ERP software. They interact with the users who are the proverbial 'bill payers' in the whole scheme. Their interaction with the users is at the highest level during the implementation stage. They have very good knowledge of the software, but lack functional knowledge or implementation knowledge. For example they are adept at answering 'how an aspect of the code works', or ' what does it take to modify a code'. They cannot answer the questions on 'what does it take to make the code work for this client', or 'to what extent the code (or the process needs to be modified to make it work'.

The implementers are the experts who are supposed to know the complete functionality of the software. They are supposed to understand the required functionality of the clients' organization from the users and establish the compatibility between the system functionality and client functionality. This is established in one of the three ways-either there is a perfect match between the two functionalities, or the system is modified (this route is least preferred by the implementers), or the business process in reengineered (much to the chagrin of the users). This team is supposed to be the 'know-it-all-experts' in the implementation process and are the most expensive. They interact with all the other players in the team. The only useful methodology that combines these is sociotechnical systems. The users are the 'bill payers' and functional experts. They are supposed to define the required functionality to the implementers.

From an ergonomic viewpoint the main concern here is in the process of interaction itself. The team members have different expectations, different skill levels, different understanding of what the system capabilities are vis-àvis required functionality and speak different languages (in a professional sense). This is not uncommon among other teams such as 'Quality improvement team' or 'Trouble shooting team'. However, these teams have a much narrower focus in problem area, problem definition, solution development and in solution implementation. ERP system implementations, however, are much larger in scope, cost and in all other aspects. Typically ergonomists specialize working on the interactions among the humanmachine-task-environment system framework (Wilson, 1999). Extension of that expertise into the realm of information systems should be natural. Ergonomists should investigate interaction processes in these large-scale implementations and develop the required paradigm. As reported by Wilson 
(1999), good understanding of the interactions will go towards a better human centered implementation methods, instead of technology centered implementation methods.

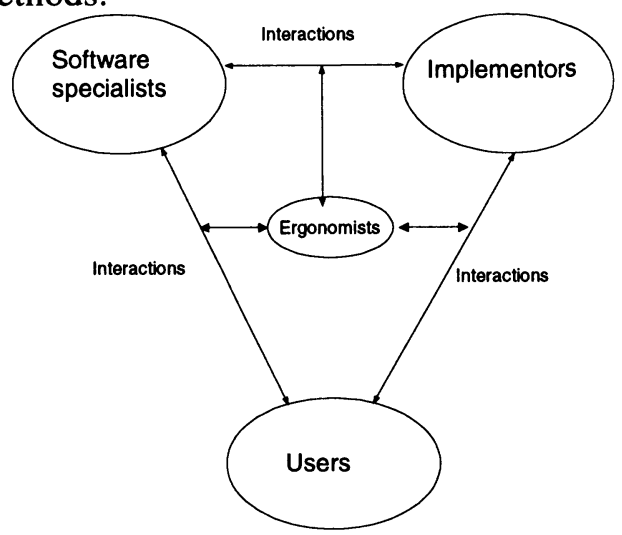

Figure 2: Interactions among the team members

\section{User training concerns}

Training is the next major area of concern in the implementation process. Typically in the implemented stage, a number of processes end up reengineered, to suit the system functionality. The user training are, unfortunately, not designed from a user need viewpoint, but are designed from a system viewpoint. This results in general frustration among all users. Further many vendors use third-party training organizations to support their software installations. To make things worse, typically trainers are often novice users themselves of the ERP package. Most of the training -is offthe-shelf as well which means trainers have not taken the time to understand the particular contextual environment in which implementation will occur.

\section{CONCLUSION}

In summary, ERP systems have not lived up to their initial promise and hype. The main reasons are costly implementation, and a technology driven paradigm. A company was quoted as saying, "and we really believe this is an organizational and a reengineering revolution and not a software exercise" (Hughes, 1999).

The best practices defined by the software are typically lean solutions based on a business process reengineering approach (Hammer and Champy, 1993). As a final quote, a spokesperson for another aerospace manufacturer plans to "lean those rascals down" before an ERP computer system is installed (Hughes, 1999). Such an approach means that the major costs are 
in the organizational side of implementation, rather than in the costs of computer hardware and software. In the current climate of mergers between large organizations, legacy processes as well as legacy information technology need to be changed anyway, so that the ERP solution is seen as particularly timely.

However lean solutions have been questioned in the ergonomics literature because of their implications for Tayloristic job design, and their tight coupling of previously buffered processes. In addition, there has been a long and generally successful effort at implementing information technology from a human factors and sociotechnical perspective (Eason, 1988). Neither of these considerations has been found in the current ERP literature.

\section{REFERENCES}

Buckhout, S., Frey, E., and Nemee, J. (1999). Making ERP succeed: Turning fear into promise, IEEE Engineering Management Review, Fall 1999, 116-123.

Davenport, T. H. (1998). Putting the enterprise into the enterprise system, In Harvard Business Review 76 (4), 121-131.

Eason, K (1988). Information technology and organizational change. London: Taylor and Francis.

Hammer, M. and Champy, J. (1993). Reengineering the corporation. New York: Harper Business

Hendrick, H, and Kleiner, B (2000). Macroergonomics: An Introduction to Work System Design.

Hughes, D (1999) Aerospace invest billing in ERP software, processes. Aviation Week and Space Technology, Jan 25,1999, 68-76.

Scheer, A.W., and Habermann, F. (2000). Making ERP a success, Communications of ACM, April 2000, 43(4), 57.

Taylor, J.C. (199X), Participative design: Linking BPR and SAP with an STS approach, Journal of Organizational Change Management, 11(3), pp

Wilson, J. (1999), Interactions as the focus for human centered systems, Proceedings of the Conference on TQM and Human Factors, Linkoping, pp 35-43. 